\title{
Synthesis of Hemoglobin F in Adult Simian
}

\section{Erythroid Progenitor-derived Colonies}

\author{
Roger M. Macklis, Jamshid Javid, Jeffrey M. Lipton, Michele Kudisch, \\ Penelope K. Pettis, and David G. Nathan, Divisions of Hematology and \\ Oncology of the Children's Hospital Medical Center and Pediatric Oncology, \\ Sidney Farber Cancer Institute and the Department of Pediatrics, Harvard \\ Medical School, Boston, Massachusetts 02115; Division of Hematology and \\ Oncology of the Department of Medicine, New York University School of \\ Medicine, New York 10016
}

\begin{abstract}
A BSTRACT The simian hematopoietic system is known to respond to anemic stress with the production of erythrocytes containing large amounts of fetal hemoglobin. To determine the regulatory mechanism responsible for hemoglobin $F(\mathrm{HbF})$ production in stress erythropoiesis, adult simian bone marrow cells were cultured in plasma clots in the presence or absence of erythropoietin and burst-promoting activities, and the $\mathrm{HbF}$ content of progenitor-derived colonies was determined by radioimmunoligand assay. Three classes of erythroid progenitors were detected: BFU-E, CFU-E, and a very mature cohort of dense highly erythropoietin-responsive cells (HERC). These classes varied in inverse proportion to their maturity with respect to their potential for $\mathrm{HbF}$ accumulation in the colonies to which they give rise. Both erythropoietin and burst-promoting activity stimulated $\mathrm{HbF}$ production, particularly in colonies derived from immature progenitors. For example, under conditions of high erythropoietin stimulation, BFU-E colonies contained 13.7-37.7\% $\mathrm{HbF}$, CFU-E colonies contained 2.8-13.5\% $\mathrm{HbF}$, and HERC colonies $0-1 \% \mathrm{HbF}$.

These results suggest that under nonstress conditions simian erythrocytes are derived almost entirely from HERC progenitors and proerythroblasts in which gamma chain synthesis is suppressed. During stress erythropoiesis, augmented $\mathrm{HbF}$ accumulation could be explained by the rapid entrance into the marrow of proerythroblasts directly derived from immature progenitors. Gamma chain production in these proerythroblasts is additionally regulated by the changes
\end{abstract}

Address reprint requests to Dr. David G. Nathan, Children's Hospital Medical Center, Boston, MA 02115.

Received for publication 6 April 1982 and in revised form 12 July 1982. in environmental erythropoietin and burst-promoting activities.

\section{INTRODUCTION}

The regulation of fetal hemoglobin $(\mathrm{HbF})^{1}$ production in adult erythrocytes has been the subject of intensive investigation (1). On the basis of erythroid cell culture experiments and qualitative fluorescent antibody analysis, Papayannopoulou et al. (2) originally suggested that the extent of reactivation of $\mathrm{HbF}$ synthesis in cultured erythroid colonies depends on the state of maturity of the erythroid progenitors from which the colonies are derived. Recently, other investigators have found evidence that the reactivation of $\mathrm{HbF}$ production in adult erythroid colonies may be less contingent on the state of progenitor maturity than on the particular environmental conditions under which the progenitor was cultured. For example, Peschle et al. (3) presented evidence that erythroid burst-forming unit (BFU)-E subcolonies and colony-forming unit (CFU)$\mathrm{E}$ colonies synthesize equal relative amounts of $\mathrm{HbF}$, and Dover et al. (4) have shown that the percentage of $\mathrm{HbF}$-laden cells in colonies derived from adult human bone marrow BFU-E does not differ significantly from that found in the more mature CFU-E colonies. Furthermore, Terasawa et al. (5) have found that factors derived from $T$ cells, such as burst-promoting activity (BPA), may influence $\mathrm{HbF}$ production in erythroid colonies. This controversy has been further complicated by the finding that gamma and beta globin

\footnotetext{
${ }^{1}$ Abbreviations used in this paper: BFU, burst-forming units; BPA, burst-promoting activity; CFU, colony-forming units; $\mathrm{HbA}$, adult hemoglobin; $\mathrm{HbF}$, fetal hemoglobin; HERC, highly erythropoietin-responsive cells.
} 
chains are expressed asynchronously in culture (6-8), which leaves open the possibility that experimental results based on radiolabeled biosynthetic studies might be strongly influenced by the extent of colony hemoglobinization at the time the cultures are assayed (9).

DeSimone et al. (10) have shown that hypoxic or phenylhydrazine-stressed baboons are capable of very brisk erythropoiesis, during which peripheral blood levels of $\mathrm{HbF}$ rise from $<1$ to $\geq 40 \%$ of the total erythrocyte hemoglobin, and that $\mathrm{HbF}$ is the predominant hemoglobin synthesized in the cultured erythroid progenitor-derived colonies of such experimental animals (11). These findings, together with our previous observations that the erythroid colonies of normal rhesus monkeys appear rapidly in plasma clot culture, lyse soon after maximal hemoglobinization, and incorporate relatively large amounts of labeled leucine into gamma chains (12), prompted our decision to study these animals in more detail. Our purpose was to define the interrelated influences of erythroid progenitor maturity and of two hormonal factors, erythropoietin and BPA (both known to increase in circulating activity during stress erythropoiesis) $(13,14)$ on globin gene expression in vitro. In order that our conclusions not be influenced by potential artifacts of short-term labeling, we used instead a radioligand immunoassay to measure quantitatively the amounts and proportions of $\mathrm{HbA}$ and $\mathrm{HbF}$ found in the pooled completed simian bone marrow erythroid colonies cultured in plasma clots. Our results show that the potential for $\mathrm{HbF}$ expression in colonies derived from erythroid progenitors is indeed inversely proportional to progenitor maturity, but that culture conditions determine the actual extent of $\mathrm{HbF}$ production in the colonies derived from immature progenitors that are capable of significant gamma gene expression.

\section{METHODS}

Bone marrow aspiration and mononuclear cell preparation. Seven normal adult rhesus monkeys (Macaca mulatta) were the subjects of 13 unique experiments. The animals were anesthetized with ketamine (100-200 mg injected i.m.) and bone marrow samples aspirated from the posterior iliac crests. Multiple aspirates were diluted 1:1 with alpha medium (15) and centrifuged on $15 \mathrm{ml}$ Ficoll-Hypaque (Pharmacia Fine Chemicals, Uppsala, Sweden) for $30 \mathrm{~min}$ at 400 $g$ and $22^{\circ} \mathrm{C}$ to separate the nucleated hematopoietic cells (interface layer) from mature erythrocytes (pellet). The interface was collected, resuspended in $10 \mathrm{ml}$ alpha medium, and recentrifuged under the same conditions on $5 \mathrm{ml}$ FicollHypaque for $30 \mathrm{~min}$ to eliminate most of the remaining erythrocytes. The interface was again collected and an aliquot fixed and stained to determine the percentages of mature erythrocytes and recognizable immature erythrocytes found in the final cell suspension. Cell suspensions prepared in this way generally had $<4 \%$ erythrocytes and essentially no recognizable erythroid precursors. The cells were then washed three times in alpha medium, counted, and resuspended in alpha medium at 10 times the final plasma clot culture concentration.

Cell culture. To obtain sufficiently large numbers of erythroid colonies, mononuclear cells were plated at 5-7 $\times 10^{5}$ cells $/ \mathrm{ml}$, using the plasma clot system described elsewhere $(15,16)$. Anemic sheep plasma erythropoietin (Connaught Medical Research Laboratories, Willowdale, Ontario, Canada, Step III) was reconstituted with National Collection of Type Cultures (NCTC)-109 (15) and added to the culture mixture. In certain experiments Mo-line hairy cell leukemia supernate (17), generously provided by Dr. David Golde, was added as a source of BPA to the plasma clot mixture ( $10 \%$ by volume, replacing an equal volume of NCTC-109). Three to six $0.1-\mathrm{ml}$ vol clots were used for morphologic studies and colony counts, and 30-50 0.1-ml clots were pooled for each data point in the radioligand immunoassay of adult hemoglobin ( $\mathrm{HbA})$ and $\mathrm{HbF}$. In those cases where exact quantitation of input background hemoglobin was desired, $500.1-\mathrm{ml}$ cultures were prepared with mononuclear cells that had been irradiated with $1,500 \mathrm{rad}$ at $500 \mathrm{rad} / \mathrm{min}$ before plating. Initial studies showed no erythrocyte lysis at this level of radiation, although all cell proliferation was prevented and no hemoglobinized colonies formed in these clots. The irradiated clots were incubated, harvested, and assayed together with experimental samples to provide an estimate of the background hemoglobin in the cultures derived from mature erythrocytes added at the time of culture initiation.

Simian CFU-E colonies were harvested on day 3 in culture, whereas simian BFU-E colonies were harvested on day 7-9 (see text). On the day of harvest, several $0.1-\mathrm{ml}$ clots were squashed, fixed, and benzidine stained $(15,16)$. Clots for hemoglobin analysis were pooled, gently suspended in $15 \mathrm{ml}$ of alpha medium and washed twice at $300 \mathrm{~g}$ for $10 \mathrm{~min}$ at $4^{\circ} \mathrm{C}$. $10 \mu \mathrm{l}$ of packed sheep erythrocytes were added to provide carrier hemoglobin, and the mixture was once again centrifuged at $300 \mathrm{~g}$ for $10 \mathrm{~min}$ at $4^{\circ} \mathrm{C}$. The supernate was removed and discarded. The pelleted clots and carrier erythrocytes were resuspended in $200 \mu \mathrm{l}$ of sterile distilled water. These mixtures were sonicated (3-4 5-s bursts, at low output) and the resulting cell lysates centrifuged at $800 \mathrm{~g}$ for $10 \mathrm{~min}$. The hemoglobin-containing supernate was removed and the volume measured. These sonicates were maintained at $4^{\circ} \mathrm{C}$ until they were assayed.

The extent of erythroid precursor maturity and the level of hemoglobinization within the precursors found in pooled colonies was determined by releasing hemoglobinized cells from plasma clots with gentle pronase treatment (15). The released cells were then washed, centrifuged, and stained with Wright-Giemsa stain.

Radioimmunoligand assay. The hemoglobin contained in the plasma clot sonicates was assayed using a radioligand assay for $\mathrm{HbA}$ and $\mathrm{HbF}$ as described in detail elsewhere (18). Briefly, several dilutions of each sample were incubated for $0.5 \mathrm{~h}$ with an excess of each of two antisera, one specific for fetal Rhesus hemoglobin alone, the other equally reactive with $\mathrm{HbF}$ or $\mathrm{HbA}$. The immune complexes thus formed were bound to a protein A-bearing strain (Cowan 1) of Staphylococcus aureus. The immunologically unreactive hemoglobins were removed by washing the pelletted bacteria. The hemoglobin specifically retained was then quantitated by its ability to bind a calibrated sample of ${ }^{125}$ I-haptoglobin. Standard curves were constructed under identical conditions using known amounts of Rhesus $\mathrm{HbF}$ and $\mathrm{HbA}$ and were included in each assay. 
Initial calibration experiments were performed to determine the sensitivity of the assay. Dilutions of adult and fetal erythrocytes in three different proportions ranging from 5 to $50 \% \mathrm{HbF}$ were made and aliquots of $10^{5}-10^{6}$ erythrocytes were placed in plasma clots, allowed to stand for $1 \mathrm{~h}$, and harvested, washed, and sonicated as outlined above. The sonicates were assayed in a blind determination and the results of the radioligand immunoassay compared to the known inputs of these hemoglobins. The fraction of $\mathrm{HbF}$ determined by the assay was within $5 \%$ of the expected values.

Density centrifugation. Estimates of progenitor cell density were made by analysis of Percoll density centrifugation behavior as described by Salvado and Sytkowski (19). Briefly, $9 \mathrm{ml}$ of Percoll were made isotonic by the addition of 0.72 $\mathrm{ml}$ of NCTC-109 and $0.28 \mathrm{ml}$ of sterile $\mathrm{H}_{2} \mathrm{O}$. The $\mathrm{pH}$ was adjusted to 7.4 with $1.0 \mathrm{~N} \mathrm{HCl}$. This stock solution was termed $100 \%$ Percoll. Lower density Percoll solutions were prepared by diluting this $100 \%$ Percoll solution with NCTC109. The density of these dilutions were calculated from their refractive indices as described (19). Block gradients were constructed in $15-\mathrm{ml}$ centrifuge tubes using four blocks of $80,70,60$, and $50 \%$ Percoll (bottom to top) layered gently on top of each other. These four blocks were overlayed with 30-60 $\times 10^{6}$ washed bone marrow cells suspended in $3 \mathrm{ml}$ of a 1:1 mixture of 50\% Percoll and NCTC-109 media. The gradients were centrifuged at room temperature, $400 \mathrm{~g}$, for $40 \mathrm{~min}$. Each Percoll block and each interface was collected, and the cells contained in each of these fractions were washed, counted, and cultured as described above.

\section{RESULTS}

Morphology of simian progenitor-derived colonies. Fig. $1 \mathrm{~A}$ and $\mathrm{C}$ depicts simian CFU-E and BFU-E derived colonies cultured for 3 and $7 \mathrm{~d}$, respectively, in the presence of $2 \mathrm{U} / \mathrm{ml}$ of erythropoietin. CFU-E colonies contain 8-16 hemoglobinized cells while BFU-E colonies contain 100-200 cells. Fig. 1B depicts the morphology of colonies that proliferate and hemoglobinize in $3 \mathrm{~d}$ in the absence of added erythropoietin (see below). They contain 4-8 hemoglobinized cells.

Fig. 2 shows a representative Wright-stained cytocentrifuged preparation of cells released by pronase treatment from plasma clots containing BFU-E colonies on the day of peak colony hemoglobinization. Relatively immature erythroid cells predominate. There was no significant difference between the mor-

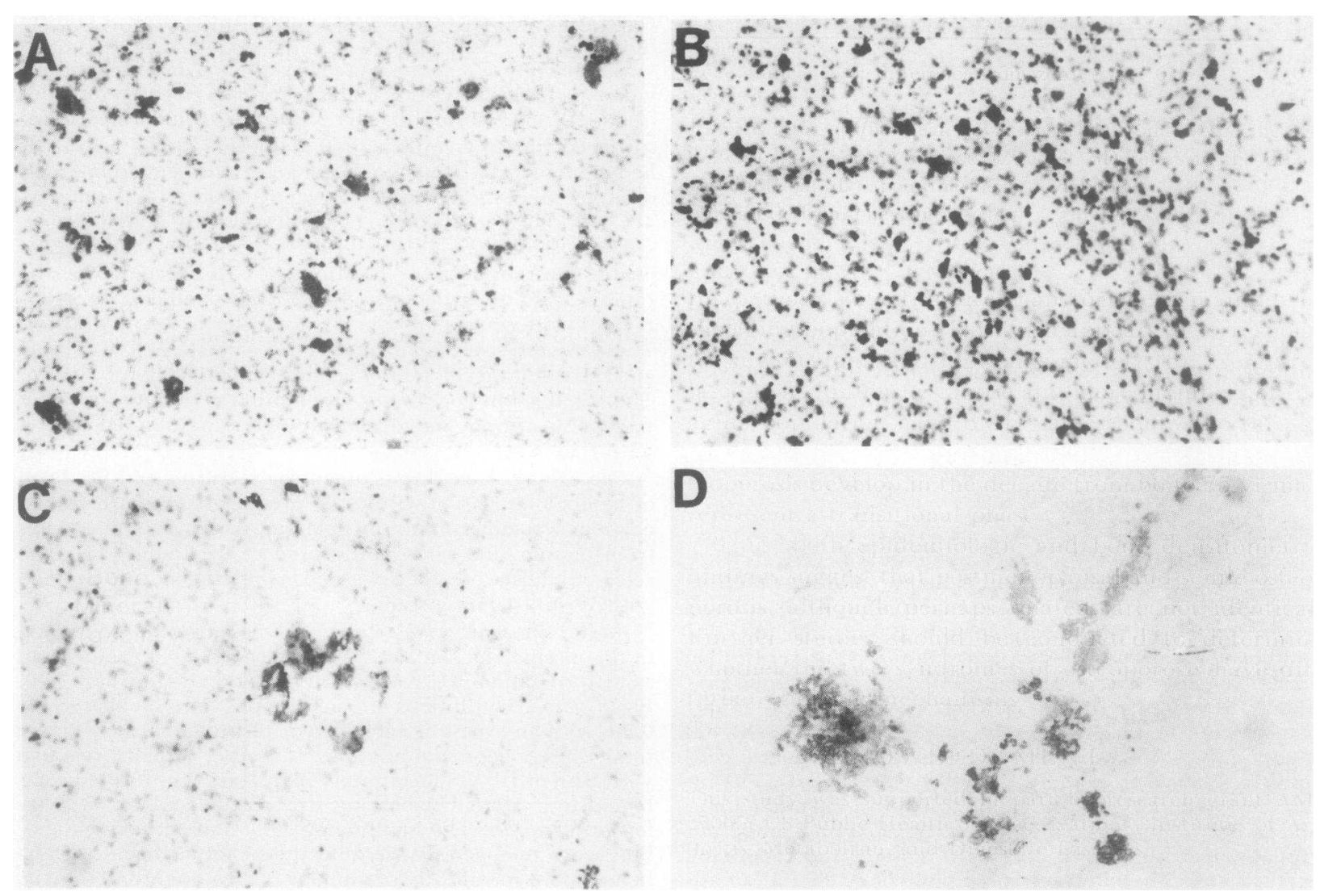

FIgURE 1 Photomicrographs at equal magnification of hematoxylin and benzidine stained simian CFU-E (A), HERC (B), 7-d BFU-E (C), and 9-d BFU-E-derived colonies (D). The HERC-derived colonies were grown in the absence of added erythropoietin. 


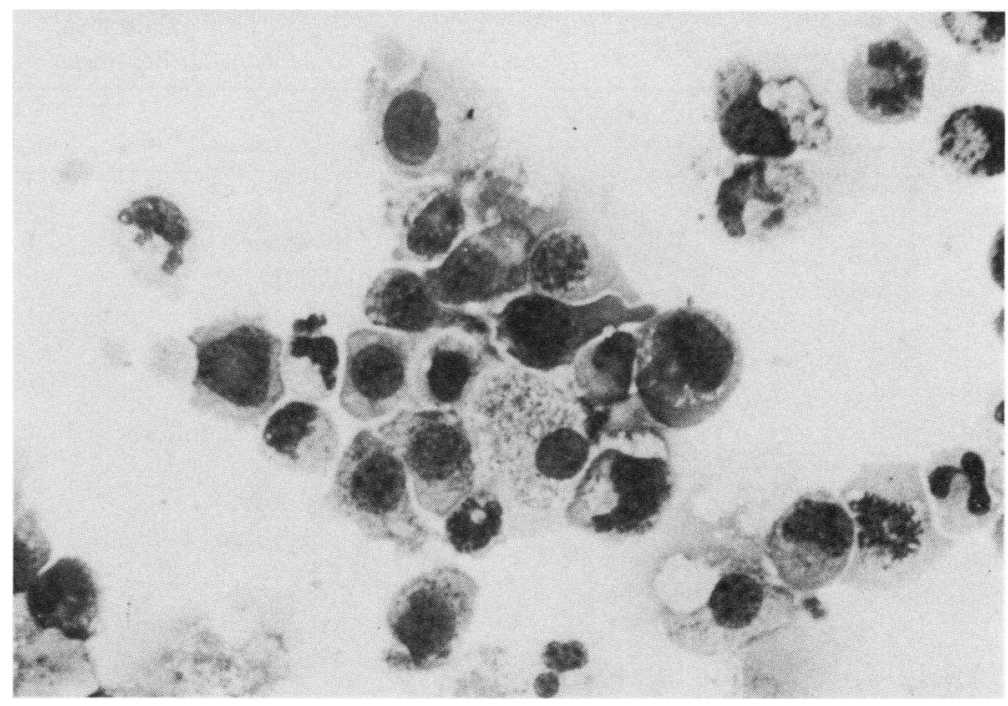

FIGURE 2 Photomicrograph of a typical cluster of erythroid cells released by pronase treatment from a plasma clot culture of simian BFU-E-derived colonies, cytocentrifuged and stained with the Wright-Giemsa technique. Most of the erythroid cells are midnormoblasts, but some basophilic erythroblasts are present.

phologically perceived level of erythroblast maturity in cells released from CFU-E-derived colonies and those released from BFU-E-derived colonies. Although some selective losses of mature cells may occur during pronase treatment, these results show that differences in $\mathrm{HbF}$ content (see below) between CFU-E- and BFUE-derived colonies cannot be readily ascribed to putative differences in the extent of colony maturation.

Effects of increasing activities of crude erythropoietin on simian colony frequency and morphology. Previous studies have demonstrated that the process of erythroid progenitor maturation involves a gradual decrease in the level of erythropoietin required for maximal colony growth (20). Fig. 3 is a representative erythropoietin dose-response curve showing the effect of increasing activities of crude erythropoietin on simian CFU-E- and BFU-E-derived colony numbers. As expected, peak CFU-E colony frequency occurs at a lower level of erythropoietin than does peak BFU-E colony frequency. Although there is no BFU-E colony formation in the absence of added erythropoietin, $\sim 20 \%$ of maximal CFU-E colony growth is expressed at zero erythropoietin, where zero represents no addition of sheep plasma erythropoietin to the culture. This subset of CFU-E, which proliferates in the absence of added erythropoietin (Fig. 1B), can be increased to include $\sim 40 \%$ of maximal CFU-E frequency if the marrow cells are initially incubated for $\mathrm{l} \mathrm{h}$ in $2 \mathrm{U} / \mathrm{ml}$ of erythropoietin, and then washed twice before the start of the culture. Colonies formed from these cells hemoglobinize slightly earlier than those derived from CFU-E. We refer to these CFU as highly erythropoietin-responsive cells (HERC). Table I provides a summary of differences between CFU-E and HERC and the colonies to which they give rise.

Determination of amounts and proportions of $\mathrm{HbA}$ and $\mathrm{HbF}$ in simian BFU-E-, CFU-E-, and HERC-derived colonies. Table II summarizes the results of eight experiments in which simian erythroid progenitor-derived colonies were cultured at $2 \mathrm{U}$ of erythropoietin $/ \mathrm{ml}$, as described above. The resultant CFUE- and BFU-E-derived colonies were harvested, sonicated, and the released hemoglobin assayed with the radioligand immunoassay. The data indicate that total

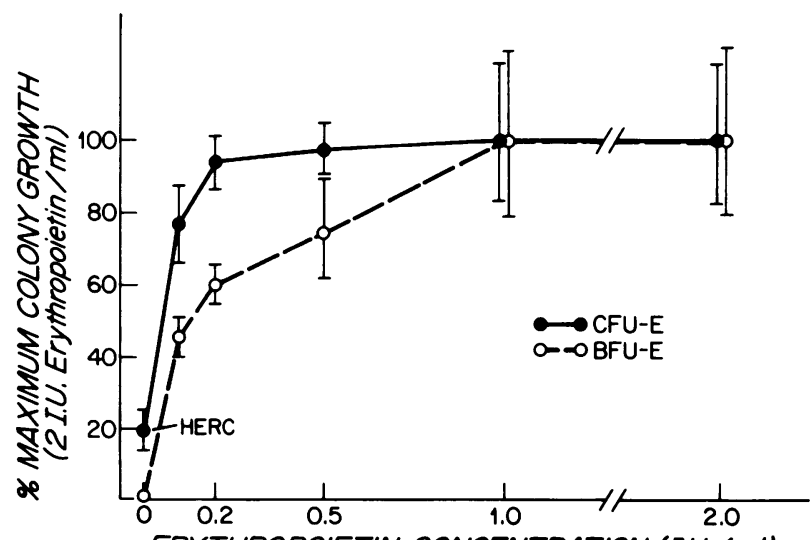

ERYTHROPOIETIN CONCENTRATION (I.U./mI)

Figure 3 Typical erythropoietin dose-response curve for adult simian CFU-E- and BFU-E-derived colonies. The CFU-E detected at zero added erythropoietin are designated as HERC-derived colonies. 
TABLE I

Comparison of CFU-E and HERC

\begin{tabular}{lcc}
\hline & CFU-E & HERC \\
\hline $\begin{array}{l}\text { Colonies } / 10^{5} \\
\text { Days to maximal colony } \\
\text { formation }\end{array}$ & $128-1,409$ & $78-546$ \\
$\begin{array}{l}\text { Cells per colony } \\
\text { Erythropoietin added for } \\
\quad \text { maximal colony } \\
\quad \text { formation, } U / m l\end{array}$ & $3-4$ & $2-3$ \\
$\begin{array}{l}\text { Peak on Percoll density } \\
\text { gradient, } \mathrm{g} / \mathrm{cm}^{3}\end{array}$ & $8-16$ & $4-8$ \\
\hline
\end{tabular}

CFU-E were measured at $2 \mathrm{U}$ erythropoietin/ml culture and HERC at either no added erythropoietin or after $1 \mathrm{~h}$ exposure to $2 \mathrm{U} / \mathrm{ml}$ erythropoietin and no further addition of the hormone.

hemoglobin recovery closely approximated the expected hemoglobin content of the colonies, if one assumes a mean hemoglobin content of $20 \mathrm{pg} /$ cell and an average of 10 cells/CFU-E-derived colony and 200 cells/burst. Furthermore the $\mathrm{HbF}$ production of BFUE-derived colonies exceeded that of CFU-E-derived colonies on a relative and absolute basis. In four experiments, set out in Table III, HERC colony growth was sufficiently greater than the background hemoglobin attributed to mature erythrocytes (estimated from parallel studies of irradiated culture plates; see Methods) to allow a reliable determination of their hemoglobin proportions. These HERC colonies were defined as the subset of CFU-E that develop in the absence of added erythropoietin. They contained virtually no $\mathrm{HbF}$.
TABLE III

HbF in HERC-derived Colonies

\begin{tabular}{|c|c|c|c|c|}
\hline $\begin{array}{c}\text { Unique } \\
\text { experiment no. }\end{array}$ & Sample & Colonies $/ 10^{5}$ & Hemoglobin & $\mathrm{HbF}$ \\
\hline & & & $n g / m l$ & \% \\
\hline \multirow[t]{5}{*}{2} & Irradiated culture & $\mathbf{0}$ & 21 & $\mathbf{0}$ \\
\hline & HERC & & & \\
\hline & 0 Epo & $197 \pm 40$ & 238 & 0 \\
\hline & 1 h Epo & $377 \pm 41$ & 324 & $\mathbf{0}$ \\
\hline & CFU-E & $907 \pm 68$ & 627 & 9.9 \\
\hline \multirow[t]{5}{*}{3} & Irradiated culture & $\mathbf{0}$ & ND & - \\
\hline & HERC & & & \\
\hline & 0 Epo & 109 & 144 & 0 \\
\hline & 1 h Epo & $78 \pm 28$ & 138 & 0 \\
\hline & CFU-E & $1,130 \pm 112$ & 1,595 & 13.5 \\
\hline \multirow[t]{5}{*}{5} & Irradiated culture & $\mathbf{0}$ & 188 & 0 \\
\hline & HERC & & & \\
\hline & 0 Epo & $202 \pm 27$ & 406 & $\mathbf{0}$ \\
\hline & 1 h Epo & $536 \pm 82$ & 349 & $\mathbf{0}$ \\
\hline & CFU-E & $1,153 \pm 87$ & 847 & 2.8 \\
\hline \multirow[t]{5}{*}{9} & Irradiated culture & $\mathbf{0}$ & 78 & $\mathbf{0}$ \\
\hline & HERC & & & \\
\hline & 0 Epo & ND & & \\
\hline & 1 h Epo & $546 \pm 109$ & 519 & 0.2 \\
\hline & CFU-E & $980 \pm 218$ & 1,925 & 1.0 \\
\hline
\end{tabular}

Cultures performed for the times and under conditions described in text. Irradiated cultures were done to determine nanograms per milliliter of hemoglobin carried inadvertantly into the culture as mature erythrocytes. The assay of hemoglobin was not performed in the irradiated culture of experiment 3 , but inspection of the cultures on day 3 revealed that erythrocytes were virtually absent. HERC were cultured at no added erythropoietin (0 epo) or after $1 \mathrm{~h}$ exposure to $2 \mathrm{U}$ erythrpoietin/ml $(1 \mathrm{~h}$ epo).

TABLE II

$H b F$ in CFU-E- and BFU-E-derived Colonies

\begin{tabular}{cccccrr}
\hline $\begin{array}{c}\text { Unique } \\
\text { experiment no. }\end{array}$ & CFU-E & Hemoglobin & HbF & BFU-E & Hemoglobin & HbF \\
\hline & colonies $/ 10^{s}$ & $n g / m l$ & $\%$ & colonies $/ 10^{s}$ & $n g / m l$ & $\%$ \\
1 & $1,327 \pm 6$ & 1,235 & 8.2 & $43 \pm 5$ & 929 & 37.7 \\
2 & $907 \pm 68$ & 627 & 9.9 & $39 \pm 4$ & 563 & 33.5 \\
3 & $1,130 \pm 112$ & 1,595 & 13.5 & $52 \pm 5$ & 2,996 & 25.4 \\
4 & $1,199 \pm 98$ & 1,054 & 7.6 & $85 \pm 10$ & 1,333 & 34.8 \\
5 & $1,153 \pm 87$ & 847 & 2.8 & $66 \pm 11$ & 963 & 31.6 \\
6 & $128 \pm 25$ & 276 & 13.2 & $35 \pm 7$ & 996 & 27.2 \\
7 & $727 \pm 42$ & 1,148 & 12.1 & $41 \pm 9$ & 936 & 18.9 \\
8 & $1,409 \pm 100$ & 2,207 & 3.9 & $123 \pm 13$ & 2,568 & 13.7 \\
\hline
\end{tabular}

In this and all subsequent tables, except where indicated, CFU-E and BFU-E cultures were performed at $2 \mathrm{U}$ erythropoietin and $5 \times 10^{5}$ marrow cells $/ \mathrm{ml}$ of plasma clot. Therefore, colonies $/ 10^{5}$ must be multiplied by 5 in order to compare colony number with total recovered hemoglobin. The latter and percentage of $\mathrm{HbF}$ were extracted from 3- to 5-ml clot, measured at several dilutions and quantified from a standard curve as described in the text. Since the assay is linear, the dilutions gave virtually identical results and therefore a single value for both total hemoglobin and $\mathrm{HbF}$ is provided. 
TABLE IV

Effect of Erythropoietin and Culture Time on HbF Production

in BFU-E-derived Colonies (10) ${ }^{\circ}$

\begin{tabular}{|c|c|c|c|c|c|c|}
\hline \multicolumn{4}{|c|}{$0.5 \mathrm{U}$ erythrpoietin $/ \mathrm{ml}$} & \multicolumn{3}{|c|}{$2.0 \mathrm{U}$ erythrpoietin $/ \mathrm{ml}$} \\
\hline $\begin{array}{l}\text { Time in } \\
\text { culture }\end{array}$ & Colonies $/ 10^{5}$ & Hemoglobin & $\mathbf{H b F}$ & Colonies $/ 10^{5}$ & Hemoglobin & $\mathbf{H b F}$ \\
\hline$d$ & & $n g / m l$ & $\%$ & & $n g / m l$ & $\%$ \\
\hline 7 & $19 \pm 4$ & 1,063 & 17.1 & $16 \pm 7$ & 854 & 24.0 \\
\hline 8 & $23 \pm 2$ & 1,217 & 22.7 & $9 \pm 3$ & 845 & 49.7 \\
\hline 9 & $14 \pm 8$ & 886 & 38.3 & $9 \pm 2$ & 771 & 54.4 \\
\hline
\end{tabular}

The decline in colony number between day 7 and 9 is not statistically significant. Note the absolute as well as relative increase in $\mathrm{HbF}$ between days 7 and 9 .

- Unique experiment number.

Effects of culture time on the HbF content of $B F U$-E-derived colonies. Because other investigators have found evidence that gamma gene expression declines with length of time in culture, $(8,21)$ it was important to investigate the effect of culture time on $\mathrm{HbF}$ content in BFU-E-derived colonies. Table IV shows the BFU-E colony frequency and the fraction of $\mathrm{HbF}$ produced by BFU-E-derived colonies cultured at 0.5 or $2 \mathrm{U} / \mathrm{ml}$ erythropoietin and harvested on days 7,8 , and 9 of culture. At both levels of erythropoietin activity, colony counts were maximal at days $7-8$ and declined thereafter as colony lysis occurred. In general, colonies that hemoglobinized on day 7 contained fewer and smaller subcolonies than those detected on day 9 (Fig. 1C, D). Despite the decline in colony frequency the relative and absolute proportion of $\mathrm{HbF}$ in the pooled colonies continued to rise from day 7 through day 9. Furthermore, the proportion of $\mathrm{HbF}$ was regularly higher in colonies cultured in the presence of $2 \mathrm{U}$ of erythropoietin than in those cultured in the presence of $0.5 \mathrm{U}$ of erythropoietin $/ \mathrm{ml}$.

Effects of increasing activities of crude erythropoietin on the proportion of $\mathrm{HbF}$ in erythroid colonies. Table $\mathrm{V}$ shows the effects of increasing activities of erythropoietin on colony frequency and the proportion of $\mathrm{HbF}$ in CFU-E-derived colonies. Note that, as described above, the colonies which hemoglobinized in the absence of added erythropoietin contained $<1 \%$ $\mathrm{HbF}$. Between 0 and $0.5 \mathrm{U} / \mathrm{ml}$ of erythropoietin, there was a gradual increase in colony frequency and percentage of $\mathrm{HbF}$, whereas from 0.5 to $2 \mathrm{U} / \mathrm{ml}$ erythropoietin there was almost a twofold increase in the proportion of $\mathrm{HbF}$ without a significant increase in either colony frequency or recovered hemoglobin.

Table $\mathrm{V}$ also presents the effects of increasing erythropoietin activity on $\mathrm{HbF}$ accumulation and colony frequency in BFU-E-derived colonies. The proportion of $\mathrm{HbF}$ generally rose by a factor of 10 as erythropoietin activity was increased from 0.1 to $2 \mathrm{U} / \mathrm{ml}$. As was observed with CFU-E-derived colonies the increase in the proportion of $\mathrm{HbF}$ detected between 0.5 and $2 \mathrm{U} / \mathrm{ml}$ of erythropoietin was not accompanied by a corresponding increase in colony frequency. It is important to emphasize that the proportion of $\mathrm{HbF}$ in BFU-E colonies cultured at the lowest erythropoietin concentrations utilized $(0.1 \mathrm{U} / \mathrm{ml})$ was much lower than the proportion observed in CFU-E-derived colonies cultured at the highest erythropoietin concentration utilized $(2.0 \mathrm{U} / \mathrm{ml}$; Discussion).

Table VI provides the results of five separate studies of BFU-E-derived colony frequency and hemoglobin formation and confirms that the relative proportion and absolute content of $\mathrm{HbF}$ in such colonies increased between 0.5 and $2 \mathrm{U}$ of erythropoietin irrespective of colony frequency or total hemoglobin recovery.

TABLE V

Influence of Crude Erythropoietin on Erythroid Progenitor-derived Colonies

\begin{tabular}{|c|c|c|c|c|}
\hline & \multicolumn{4}{|c|}{ Erythropoietin activity $(\mathrm{U} / \mathrm{ml})$} \\
\hline & $\mathbf{0}$ & 0.1 & 0.5 & 2.0 \\
\hline \multicolumn{5}{|l|}{ CFU-E (7) ${ }^{\bullet}$} \\
\hline Colonies $/ 10^{5}$ & $223 \pm 20$ & $316 \pm 21$ & $687 \pm 32$ & $727 \pm 20$ \\
\hline $\begin{array}{c}\text { Hemoglobin, } \\
n g / m l\end{array}$ & 305 & 1,331 & 1,400 & 1,148 \\
\hline $\mathrm{HbF}, \%$ & 0.6 & 1.3 & 6.9 & 12.1 \\
\hline \multicolumn{5}{|l|}{ BFU-E (5) ${ }^{\bullet}$} \\
\hline Colonies $/ 10^{5}$ & 0 & $38 \pm 3$ & $61 \pm 2$ & $66 \pm 11$ \\
\hline $\begin{array}{l}\text { Hemoglobin, } \\
n g / m l\end{array}$ & 13 & 858 & 1,637 & 962 \\
\hline $\mathrm{HbF}, \%$ & $\downarrow$ & 3.6 & 14.2 & 31.6 \\
\hline
\end{tabular}

The increase in $\mathrm{HbF}$ as a function of erythropoietin activity is absolute as well as relative and has no predictable relationship to the calculated hemoglobin per colony.

- Unique experiment number.

$\ddagger$ Value below limits of accurate detection. 
TABLE VI

Influence of Crude Erythropoietin on HbF Accumulation in BFU-E-derived Colonies

\begin{tabular}{cccrr}
\hline $\begin{array}{c}\text { Unique } \\
\text { experiment no. }\end{array}$ & $\begin{array}{c}\text { Erythropoietin } \\
\text { activity }\end{array}$ & Colonies $/ 10^{5}$ & Hb & HbF \\
\hline \multirow{2}{*}{4} & U/ml & & $n g / m l$ & $\%$ \\
& 0.5 & $60 \pm 5$ & 1,502 & 17.1 \\
5 & 2.0 & $85 \pm 10$ & 1,333 & 34.8 \\
& 0.5 & $61 \pm 2$ & 1,637 & 14.2 \\
\multirow{2}{*}{8} & 2.0 & $66 \pm 11$ & 963 & 31.6 \\
& 0.5 & $148 \pm 28$ & 3,227 & 7.2 \\
11 & 2.0 & $123 \pm 13$ & 2,568 & 13.7 \\
& 0.5 & $26 \pm 5$ & 110 & 18.9 \\
& 2.0 & $59 \pm 10$ & 120 & 25.5 \\
12 & 0.5 & $19 \pm 4$ & 1,063 & 17.1 \\
& 2.0 & $16 \pm 7$ & 854 & 24.0 \\
\hline
\end{tabular}

The increase in $\mathrm{HbF}$ as a function of erythropoietin activity is both absolute and relative and has no predictable relationship to the calculated hemoglobin per colony.

Effects of BPA on simian erythroid colony frequency and proportion of HbF. Table VII shows the effects of the addition of T-cell-derived BPA to CFU$\mathrm{E}$ and BFU-E colonies cultured in the presence of 2 $\mathrm{U} / \mathrm{ml}$ of erythropoietin. BPA had no effect on CFU$\mathrm{E}$ colony frequency or $\mathrm{HbF}$ content, whereas in four of five experiments BPA slightly to markedly increased the proportion of $\mathrm{HbF}$ contained in the BFU-E-derived colonies without any predictable relationship to colony frequency or hemoglobin recovery.

\section{DISCUSSION}

This study was designed to investigate the effects of progenitor maturity and culture conditions on simian $\mathrm{HbF}$ production in culture. The investigation used techniques by which the relative and absolute $\mathrm{HbF}$ content of progenitor-derived colonies could be reliably assayed. The results show that both maturation and environmental conditions play separate roles in the regulation of $\mathrm{HbF}$ production. The finding that, under identical culture conditions, BFU-E consistently generate colonies with 2-4 times the proportion of $\mathrm{HbF}$ contained by the more mature CFU-E-derived colonies shows that the potential for $\mathrm{HbF}$ production is in general inversely proportional to the maturity of the progenitor cell from which the colony was derived. Because the peripheral blood of the unstressed rhesus monkey contains $<1 \% \mathrm{HbF}$, this model predicts the existence of a cohort of very mature erythroid progenitors which would give rise to colonies with little or no $\mathrm{HbF}$. The characteristics of this group of progenitors should include exquisite erythropoietin sen-
TABLE VII

Effect of BPA on Colony Formation and HbF Expression at $2 U$ Erythropoietin $/ \mathrm{ml}$

\begin{tabular}{|c|c|c|c|c|c|}
\hline $\begin{array}{c}\text { Unique } \\
\text { experiment no. }\end{array}$ & $\begin{array}{l}\text { Colony } \\
\text { type }\end{array}$ & $\begin{array}{l}\mathrm{BPA}^{*} \\
\text { added }\end{array}$ & Colonies $/ 10^{5}$ & Hemoglobin & $\mathrm{HbF}$ \\
\hline & & & & $n g / m l$ & $\%$ \\
\hline \multirow[t]{2}{*}{2} & BFU-E & - & $39 \pm 4$ & 563 & 33.5 \\
\hline & & + & $60 \pm 14$ & 741 & 46.5 \\
\hline \multirow[t]{4}{*}{7} & CFU-E & - & $727 \pm 42$ & 1,148 & 12.1 \\
\hline & & + & $742 \pm 85$ & 1,220 & 10.1 \\
\hline & BFU-E & - & $41 \pm 9$ & 936 & 18.9 \\
\hline & & + & $29 \pm 8$ & 808 & 21.0 \\
\hline \multirow[t]{4}{*}{8} & CFU-E & - & $1,409 \pm 100$ & 2,207 & 3.9 \\
\hline & & + & $1,564 \pm 102$ & 2,424 & 2.8 \\
\hline & BFU-E & - & $123 \pm 13$ & 2,568 & 13.7 \\
\hline & & + & $145 \pm 10$ & 1,968 & 32.1 \\
\hline \multirow[t]{2}{*}{11} & BFU-E & - & $59 \pm 10$ & 120 & 25.5 \\
\hline & & + & $60 \pm 7$ & 252 & 61.0 \\
\hline \multirow[t]{4}{*}{13} & CFU-E & - & $128 \pm 25$ & 276 & 13.2 \\
\hline & & + & $134 \pm 38$ & 233 & 15.5 \\
\hline & BFU-E & - & $70 \pm 14$ & 996 & 27.2 \\
\hline & & + & $24 \pm 4$ & 575 & 35.7 \\
\hline
\end{tabular}

- The supernate of a malignant T-cell line was added as a source of BPA to the plasma clot mixture ( $10 \%$ by vol) replacing an equal volume of NCTC-109. BPA induced a relative and absolute increase in $\mathrm{HbF}$ in the $\mathrm{BFU}-\mathrm{E}$-derived colonies developed in experiments 2,8 , and 11 , only a relative increase in experiment 13 , and had no effect in experiment 7 . There is no predictable relationship of $\mathrm{HbF}$ content to calculated hemoglobin per colony.

sitivity (and hence responsiveness to ambient levels of erythropoietin), small colony size, and early hemoglobinization. The growth characteristics of such CFU have been previously described in murine and ovine systems (22-25). The HERC, which produce 0-1\% $\mathrm{HbF}$, fulfill all of these requirements. Since we could not detect proerythroblasts in the interface layer after initial Ficoll-Hypaque preparation, we do not believe that HERC are identical to proerythroblasts. Further attempts at HERC concentration using physical separation techniques are now in progress. At present, we conclude that HERC represent a subset of relatively dense, very mature, CFU, at a stage of maturation somewhere between CFU-E and proerythroblasts. They produce colonies of erythroid cells containing almost $100 \%$ HbA.

On the basis of this support for the progenitor-maturity-based model of $\mathrm{HbF}$ regulation, it would be tempting to conclude that the increased $\mathrm{HbF}$ production observed in association with increments of crude erythropoietin activity in culture is attributable to recruitment of increasingly immature progenitors with higher erythropoietin requirements and progressively 
greater potentials for $\mathrm{HbF}$ production. Certainly, this phenomenon accounts for part of the erythropoietin dose-response effect on $\mathrm{HbF}$ in the CFU-E cohort. In such experiments the essentially $100 \% \mathrm{HbA}$ contributed by HERC colonies with no added erythropoietin is progressively diluted by hemoglobin contributed by the more immature CFU-E colonies containing significant amounts of $\mathrm{HbF}$. However, the finding that, at levels of erythropoietin $>0.5 \mathrm{U} / \mathrm{ml}$, there continues to be a sharp rise in the $\mathrm{HbF}$ percentage without a corresponding rise in colony numbers suggests that, independent of recruitment effects, some activities present in crude erythropoietin are capable of directly stimulating $\mathrm{HbF}$ synthesis. Other investigators have attributed this crude erythropoietin dose-response effect to BPA contaminating the crude erythropoietin (5).

Additional evidence for direct stimulating effects of crude erythropoietin on $\mathrm{HbF}$ synthesis can be found in an analysis of $\mathrm{HbF}$ accumulation in BFU-E-derived colonies at low levels of erythropoietin. At $0.1 \mathrm{U} / \mathrm{ml}$ of erythropoietin, BFU-E colonies accumulated only $3.6 \% \mathrm{HbF}$. If the erythropoietin dose-response effect were due entirely to recruitment phenomena, the most mature BFU-E should never produce less $\mathrm{HbF}$ than the most immature CFU-E. Because CFU-E colonies had almost entirely lysed by the time BFU-E colonies were harvested and because BFU-E colonies had not begun to hemoglobinize on day 3 , when CFU-E colonies were harvested, these results cannot be due to contamination of CFU-E-derived colonies by BFU-Ederived colonies or vice versa. Rather, these results analyzed together are most compatible with a model of $\mathrm{HbF}$ regulation involving two factors: First, the potential for $\mathrm{HbF}$ synthesis in vitro seems to be determined by the maturity of the progenitor from which the colony arose. Thus, BFU-E have an inherently greater potential for $\mathrm{HbF}$ synthesis than do CFU-E, which in turn have a greater potential for $\mathrm{HbF}$ synthesis than do HERC. Second, the actual amount of $\mathrm{HbF}$ synthesis in colonies derived from immature progenitors capable of substantial $\mathrm{HbF}$ synthesis is determined by the culture conditions. Thus, although BFUE-derived colonies are inherently capable of greater $\mathrm{HbF}$ synthesis than CFU-E-derived colonies, at low activities of crude erythropoietin this potential capacity is not fully realized. In essence, the level of maturity of a simian progenitor determines the upper limit of $\mathrm{HbF}$ synthesis in culture, but the culture conditions will determine the actual extent of $\mathrm{HbF}$ synthesis up to that limit.

Other investigators have shown that at least in man, asynchrony in the expression of gamma and beta chains production results in a decline in overall $\mathrm{HbF}$ synthesis and accumulation as time in culture increases (21). In contrast, we found that the relative proportion and absolute content of $\mathrm{HbF}$ in pooled BFU-E colonies increased as time in culture is protracted. The differences in synthetic ratios would be reconciled in part if we assume that $\mathrm{HbF}$-rich colonies tend to persist in culture while the HbA-rich colonies (derived from more mature progenitors) begin to lyse. Thus, even if relative gamma chain synthesis declines in each individual colony as hemoglobinization proceeds (i.e., the gamma/beta + gamma synthetic ratio decreases), the relative accumulation of gamma globin in the residual colonies which have not yet lysed would increase owing to preferential loss of $\mathrm{HbA}$-rich colonies initially derived from more mature progenitors. On the other hand, relative lysis of mature colonies cannot totally explain the phenomenon because we found that the absolute amount of $\mathrm{HbF}$ in the culture also increases with time. Since environmental conditions have a profound effect on $\mathrm{HbF}$ accumulation in BFU-E-derived colonies, the observed differences between laboratories are probably the results of different culture techniques.

The effects of BPA on $\mathrm{HbF}$ accumulation are not established. Previous studies have suggested that the influence of BPA on hemoglobin accumulation is primarily directed at colonies derived from immature progenitors $(5,26)$. Our results showing that BPA has little or no effect on the hemoglobin accumulation of relatively mature simian CFU-E-derived colonies are in close agreement with such conclusions. Although our experiments in which BPA activity was added to BFU-E did not provide absolutely consistent results, in most of the studies the addition of this product of a malignant $\mathrm{T}$-cell line did result in an increase in $\mathrm{HbF}$ accumulation of modest-to-striking proportions in BFU-E-derived colonies. This result suggests that in conditions of stress, when both erythropoietin and BPA are increased, the two hormones may collaborate in some fashion to induce maximal $\mathrm{HbF}$ production in the colonies derived from immature progenitors.

The implication of these in vitro studies for the regulation of in vivo erythropoiesis can be best appreciated in the context of the experiments of Alpen and Cranmore, $(27,28)$ who examined cellular dynamics and the regulation of erythropoiesis in the normal and acutely bled dog and those of Deubelbeiss et al. (29), who measured the total proerythroblast content of canine marrow. The former investigators labeled hemoglobinizing proerythroblasts in vivo with ${ }^{59} \mathrm{Fe}$ and sequentially analyzed the proportion of labeled and unlabeled proerythroblasts to measure their renewal from an unlabeled pool and their doubling times. In the bled animals there was a rapid surge of unlabeled cells into the labeled proerythroblast compartment without any change in the doubling time of the latter or in the number of divisions between proerythroblasts and reticulocytes. Alpen and Cranmore therefore con- 
cluded that during stress erythropoiesis there was "an influx of a larger proportion of freshly differentiated proerythroblasts into the hemoglobinizing cohort" (28). Further analysis of their data and that of Dubelbeiss et al. (29) show that under normal conditions self-replicating proerythroblasts largely maintain the erythrocyte pool, being renewed from the immature progenitor compartment at a rate of $<10 \% / \mathrm{d} .^{2}$ In contrast, in the bled animal, nearly the entire burden of accelerated reticulocyte production is borne by rapid influx from the immature progenitor compartment into an expanded proerythroblast pool, a renewal that approaches a rate of $120 \% / d$.

These data and our own suggest that the striking increase in $\mathrm{HbF}$-laden cells that accompanies simian stress erythropoiesis is attributable at least in part to the entry into the simian marrow of proerythroblasts derived from immature progenitors that are forced prematurely into terminal differentiation. We propose that unlike erythroblasts derived largely from the HERC and self-renewing proerythroblast compartments, the gamma globin genes of which are suppressed, the erythroblasts proximally derived from immature progenitors (CFU-E and BFU-E) are recruited into differentiation before suppression of gamma genes is completed. In addition, hemoglobinization occurs in such proerythroblasts in the presence of the high levels of erythropoietin and BPA that are observed in many anemic states. Both appear to have the capacity to induce maximal amounts of gamma globin synthesis in erythroblasts in which gamma gene suppression is sufficiently incomplete. This combination of kinetic and environmental forces influences the number of $F$ cells and the extent of $\mathrm{HbF}$ accumulation per cell in stress erythropoiesis.

Dover et al. have recently reported results of their studies of $F$ cell production in vivo $(7,30)$ and in vitro $(4,31)$. They have confirmed that in certain hemoglo-

\footnotetext{
${ }^{2}$ This conclusion is based on the following data: Dubelbeiss (29) measured the total proerythroblast content of canine marrow and found an average value of $0.17 \times 10^{9}$ proerythroblasts $/ \mathrm{kg}$ body $\mathrm{wt}$, or (assuming a blood volume of $70 \mathrm{ml}$ / kg) $0.24 \times 10^{4}$ cells $/ \mu^{3}$ blood. Alpen and Cranmore $(27,28)$ found that the daily renewal rate of normal canine proerythroblasts from the progenitor compartment is $30 \%$, or $0.07 \times 10^{4}$ cells $/ \mu^{3}$ blood $/ \mathrm{d}$. They also found that the mean number of divisions between the proerythroblast and reticulocyte compartment is 2.3 . Thus, each proerythroblast contributes an average of 5 reticulocytes. The reticulocyte production of the $\operatorname{dog}$ is $5 \times 10^{4}$ cells $/ \mu^{3}$ blood $/ \mathrm{d}$. Therefore, $10^{4}$ proerythroblasts $/ \mu^{3}$ blood are committed to daily reticulocyte production. A further $20 \%$ is committed to early death for a total commitment to differentiation of $1.2 \times 10^{4}$ cells $/ \mu^{3}$ blood $/ d$. Hence, the contribution of proerythroblasts proximally derived from the progenitor pool $\left(0.07 \times 10^{4}\right.$ cells $/ \mu^{3}$ blood $/ \mathrm{d}$ ) to daily reticulocyte production is $\sim 6 \% / \mathrm{d}$.
}

binopathic states such as sickle cell anemia and thalassemia, there is an increase in the number of erythrocytes containing detectable $\mathrm{HbF}$ ( $\mathrm{F}$ cells). The amount of $\mathrm{HbF}$ per $\mathrm{F}$ cell is often no different in these conditions than that observed in the rare circulating $F$ cells in normal individuals, $\sim 4-8 \mathrm{pg}$ of $\mathrm{HbF} /$ cell. On the other hand, the production of cells containing larger amounts of $\mathrm{HbF}(8-15 \mathrm{pg}$ of $\mathrm{HbF} /$ cell) is a regular feature of states such as posthemorrhagic anemia, bone marrow transplantation, and marrow failure. Using single cell assays, Dover et al. (4) have shown that while erythroblasts derived from human BFU-E-derived colonies contain more $\mathrm{HbF}$ per cell than cells derived from CFU-E-derived colonies, there is no significant difference in the fraction of erythroblasts containing detectable $\mathrm{HbF}$ in these colonies. Moreover, the number of circulating $F$ cells produced by an individual seems to be genetically determined, whereas the amount of $\mathrm{HbF}$ per $\mathrm{F}$ cell is not under simple genetic control (30). Thus a third factor, a genetic predisposition to express gamma genes in proerythroblasts derived from any progenitor together with the influences of progenitor maturity and environment combine to influence the total production of $\mathrm{HbF}$ in the various forms of stress erythropoiesis. Differences in genetic factors are perhaps most strikingly shown in the simian system. Though in general the capacity to produce $\mathrm{HbF}$ in response to stress is much more impressive in simians than in man, DeSimone et al. (10) have noticed a marked variability among families of baboons to respond to stress in this fashion.

The application of these results to human erythropoiesis has yet to be determined. Though certain biosynthetic and fluorescent antibody studies have suggested that reactivation of $\mathrm{HbF}$ synthesis is readily detected in human marrow cultures $(2,6)$, we found that $F$ synthesis was much lower in human marrow than in human blood progenitor cultures (15), and our preliminary quantitative studies of normal human marrow CFU-E- and BFU-E-derived colonies show that $\mathrm{HbF}$ accumulation is only $20 \%$ or less of that exhibited by rhesus monkey erythroid colonies. Further studies are now in progress with which we hope to clarify the interaction of environmental conditions, hormonal levels, cellular dynamics, and genetic predispositions in the regulation of $\mathrm{HbF}$ production in humans.

\section{ACKNOWLEDGMENTS}

The authors are grateful to Drs. Blanche Alter, Arthur Axelrad, George Dover, and David Housman for stimulating discussions of this work, and to Dr. David Golde for BPAcontaining conditioned medium.

This work was supported by U.S. Public Health Service grants P01 HL 27375-01, P01 CA 18662, and HL 19646, and by a grant from the Cooley's Anemia Foundation and the Dyson Foundation. 


\section{REFERENCES}

1. Stamatoyannopoulos, G., and A. W. Nienhuis. 1981. Hemoglobins in Development and Differentiation. Alan R. Liss, Inc., New York.

2. Papayannopoulou, T., M. Brice, and G. Stamatoyannopoulos. 1977. Hemoglobin $F$ synthesis in vitro: evidence for control at the level of primitive erythroid stem cells. Proc. Natl. Acad. Sci. USA. 74: 2923-2927.

3. Peschle, C., A. R. Migliaccio, F. Lettieri, Y. P. Maguire, M. Condorelli, A. M. Gianni, S. Ottolenghi, B. Giglioni, M. L. Pozzoli, and P. Comi. 1981. Regulation of $\mathrm{Hb}$ synthesis in ontogenesis and erythropoietin differentiation: in vitro studies on fetal liver, cord blood, normal adult blood or marrow, and blood from HPFH patients. In Hemoglobins in Development and Differentiation. G. Stamatoyannopoulos and A. W. Nienhuis, editors. Alan R. Liss, Inc., New York. 359-371.

4. Dover, G. J., T. Chan, and F. Sieber. 1981. Both early and late erythroid progenitors produce increased levels of $\mathrm{HbF}$ in culture. Blood. 58(Suppl. 1): 178 (Abstr.).

5. Terasawa, T., M. Ogawa, P. N. Porter, D. W. Golde, and E. Goldwasser. 1980. Effect of burst-promoting activity (BPA) and erythropoietin on hemoglobin biosynthesis in culture. Blood. 56: 1106-1110.

6. Papayannopoulou, T., T. Kalmantis, and G. Stamatoyannopoulos. 1979. Cellular regulation of hemoglobin switching: evidence for inverse relationship between fetal hemoglobin synthesis and degree of maturity of human erythroid cells. Proc. Natl. Acad. Sci. USA. 76: 6420-6424.

7. Dover, G. J., and S. H. Boyer. 1980. Quantitation of hemoglobins within individual red cells: asynchronous biosynthesis of fetal and adult hemoglobin during erythroid maturation in normal subjects. Blood. 56: 10821091.

8. Papayannopoulou, T., B. Nakamoto, S. Kurachi, and G. Stamatoyannopoulos. 1981. Globin synthesis in erythyroid bursts that mature sequentially in culture. $I$. Studies in cultures of adult peripheral blood BFU-Es. Blood. 58: 969-974

9. Darbre, P., S. M. Lauckner, J. W. Adamson, W. G. Wood, and D. J. Weatherall. 1981. Haemoglobin synthesis in human erythroid bursts during ontogeny: reproducibility and sensitivity to culture conditions. $\mathrm{Br}$. J. Haematol. 48: 237-250.

10. DeSimone, J., S. I. Biel, and P. Heller. 1978. Stimulation of fetal hemoglobin synthesis in baboons by hemolysis and hypoxia. Proc. Natl. Acad. Sci. USA. 75: 2937-2940.

11. DeSimone, J., P. Heller, and J. G. Adams. 1979. Hemopoietic stress and fetal hemoglobin synthesis: comparative studies in vivo and in vitro. Blood. 54: 11761181 .

12. Alter, B. P., B. T. Jackson, J. M. Lipton, G. J. Piasecki, P. L. Jackson, M. Kudisch, and D. G. Nathan. 1981. Control of the simian hemoglobin switch at the progenitor cell level. J. Clin. Invest. 67: 458-466.

13. Nissen, C., N. N. Iscove, and B. Speck. 1979. High burstpromoting activity (BPA) in serum of patients with acquired aplastic anemia. In Experimental Hematology Today. S. J. Baum and G. D. Ledney, editors. SpringerVerlag, New York. 79-87.

14. Dukes, P. P., D. Meytes, A. Ma, G. DiRicco, J. A. Ortega, and N. A. Shore. 1978. A urinary factor which stimulates erythroid burst formation more effectively than erythropoietin. In Hemopoietic Cell Differentiation. D. W. Golde, M. J. Cline, D. Metcalf, and C. F. Fox, editors. Academic Press, Inc., New York. 119.
15. Clarke, B. J., D. G. Nathan, B. P. Alter, B. G. Forget, D. G. Hillman, and D. E. Housman. 1979. Hemoglobin synthesis in human BFU-E and CFU-E derived colonies. Blood. 54: 805-817.

16. McLeod, D. L., M. M. Shreeve, and A. A. Axelrad. 1974. Improved plasma culture system for production of erythropoietin colonies in vitro: quantitative assay for CFU-E. Blood. 44: 517-534.

17. Golde, D. W., N. Bersch, S. G. Quan, and A. J. Lusis. 1980. Production of erythroid-potentiating activity by a human T-lymphoblast cell line. Proc. Natl. Acad. Sci. USA. 77: 593-596.

18. Javid, J., P. K. Pettis, and J. E. Miller. 1981. Radio-ligand immunoassay for human hemoglobin variants. J. Immunol. Methods. 41: 247-255.

19. Salvado, A. J., and A. J. Sytkowski. 1981. Characterization of multiple erythroid progenitors available in large quantity from rabbit marrow. Exp. Hematol.(Copenh.). 9: 595-603.

20. Eaves, E., and A. C. Eaves. 1978. Erythropoietin (EP) dose-response curves for three classes of erythroid progenitors in normal human marrow and in patients with polycythemia vera. Blood. 53: 1196-1210.

21. Dean, A., A. N. Schechter, T. Papayannopoulou, and G. Stamatoyannopoulos. 1981. Heterogeneity of erythroid precursor cells. J. Biol. Chem. 256: 2447-2453.

22. Monette, F. C., P. L. Ouellette, and P. P. Faletra. 1980. Characterization of murine erythroid progenitors with high erythropoietin sensitivity in vitro. Exp. Hematol. (Copenh.). 9: 249-256.

23. Ouellette, R. L., and F. C. Monette. 1980. Erythroid progenitors forming clusters in vitro demonstrate high erythropoietin sensitivity. J. Cell. Physiol. 105: 181-184.

24. Kennedy, W. L., E. L. Alpen, and J. F. Garcia. 1980. Regulation of red blood cell production by erythropoietin: normal mouse marrow in vitro. Exp. Hematol. (Copenh.). 8: 1113-1122.

25. Roodman, G. D., J. M. Kaplan, M. E. Kaplan, and E. D. Zanjani. 1981. Effects of shortened erythropoietin exposure on sheep marrow cultures. Br. J. Haematol. 47: 195-201.

26. Kidoguchi, K., M. Ogawa, J. D. Karam, and A. G. Martin. 1978. Augmentation of fetal hemoglobin $(\mathrm{HbF})$ synthesis in culture by human erythropoietic precursors in the marrow and peripheral blood studies in sickle cell anemia and non-hemoglobinopathic adults. Blood. 52: 1115-1124.

27. Alpen, E. L., and D. Cranmore. 1959. Cellular kinetics and iron utilization in bone marrow as observed by $\mathbf{F e}^{59}$ radioautography. Ann. N.Y. Acad. Sci. 77: 753-765.

28. Alpen, E. L., and D. Cranmore. 1959. Observations on the regulation of erythropoiesis and on cellular dynamics by $\mathrm{Fe}^{59}$ autoradiography. In The Kinetics of Cellular Proliferation. F. Stohlman, Jr., editor. Grune \& Stratton, Inc., New York. 290-300.

29. Deubelbeiss, K. A., J. R. Dancey, L. A. Harker, B. Cheney, and C. A. Finch. 1975. Marrow erythroid and neutrophil cellularity in the dog. J. Clin. Invest. 55: 825832.

30. Dover, G. J., S. H. Boyer, S. Charache, and K. Heintelman. 1978. Individual variation in the production and survival of $\mathbf{F}$ cells in sickle cell disease. N. Engl. J. Med. 299: 1428-1435.

31. Dover, G. J., and M. Ogawa. 1980. Cellular mechanisms for increased fetal hemoglobin production in culture. $J$. Clin. Invest. 66: 1175-1178. 